\title{
The future of retirement and the pension system: How the public's expectations vary over time and across socio-economic groups
}

\author{
Luc Bissonnette $^{1}$ and Arthur van Soest ${ }^{2^{*}}$
}

*Correspondence:
A.H.O.vanSoest@uvt.nl
${ }^{2}$ Netspar, Tilburg University,
Warandelaan 2,5037 AB Tilburg,
The Netherlands
Full list of author information is
available at the end of the article

Springer

\begin{abstract}
We analyze expectations of the Dutch population ages 25 and older concerning future generosity of state and occupational pensions, the main pillars of the Dutch pension system. We use rotating panel data with monthly observations from 2006 until 2012 on individuals' subjective expectations concerning changes between now and ten or twenty years from now in the purchasing power of occupational pensions and of old age social security benefits, the eligibility age for old age social security benefits, and the average retirement age ten or twenty years from now. We find significant variation in expectations across socio-economic groups, with more pessimistic expectations amongst higher educated and higher income groups. We also find that expectations have gradually become more pessimistic since the onset of the economic and financial crisis, in line with the plans for reforms that will reduce pension generosity.
\end{abstract}

JEL codes: $\mathrm{D} 84, \mathrm{H} 55, \mathrm{~J} 26$

Keywords: Subjective probabilities, Old age social security, Occupational pensions

\section{Introduction}

In models of life cycle behaviour and inter-temporal decision making under uncertainty, expectations play an important role. For example, consumption, saving, and labour supply decisions of individuals and households not only depend on their current tastes and opportunities, but also on their expectations of future prices, their future income, etc. (see, for example, Feldstein (1974)).

Future expectations often remain unobserved and traditional macro- or microeconomic models typically make assumptions on how they are formed, e.g. assuming rational expectations. The conclusions from these models may be biased if the assumptions on expectations are not satisfied. To solve the problem that expectations are unobserved, many recent empirical studies aim at measuring expectations directly using survey questions. See, for example, Manski (2004) for an assessment of the validity of this approach and a recent special issue of Journal of Applied Econometrics (Bellemare and Manski 2011). Other examples are Keane and Runkle (1990) on inflation expectations, Dominitz and Manski (2005) on expectations of equity returns, Dominitz and Manski (1997), Das et al. (1999) and Dominitz (2001) on income expectations, Hurd and McGarry (1995) on length of life expectations, Stephens (2004) on job loss expectations,

(C) 2012 Bissonnette and van Soest; licensee Springer. This is an Open Access article distributed under the terms of the Creative Commons Attribution License (http://creativecommons.org/licenses/by/2.0), which permits unrestricted use, distribution, and reproduction in any medium, provided the original work is properly cited. 
Benítez-Silva and Dwyer (2005) on retirement expectations, Dominitz and Manski (2006) and Chan and Stevens (2008) on pension expectations, and Delavande and Rohwedder (2008) on expectations of old age social security income.

Pension expectations have become particularly relevant since in many industrialized countries, the ageing of the population has led to a debate on the need for pension reforms to keep the pension system sustainable (Lindbeck and Persson 2003; Zaidi 2010). Particularly since the economic and financial crisis, high retirement replacement rates can no longer be taken for granted. Recent reforms reduce the generosity of guaranteed retirement income and at the same stimulate additional voluntary pension savings, increasing awareness of pension risks and individual responsibility.

In this paper, we analyze expectations of the Dutch population aged 25 and older concerning the future generosity of the two main pillars of the Dutch system of income provision to the elderly - first pillar old age social security benefits (AOW) and second pillar occupational pensions (mandatory for almost all employees). As in many other European countries, sustainability of income provision in old age has become an important issue in public policy discussions due to the ageing of the population (Bovenberg and Gradus 2008). Generous early retirement benefits are gradually being phased out and replaced by actuarially fair flexible retirement systems. The debate has been reinforced by the financial and economic crisis, leading to additional pressure on old age social security due to government budget concerns and due to pressure on occupational pensions caused by the reduced value of the assets of occupational pension funds that invest part of their clients' pension savings in equity. The idea of working after the normal retirement age of 65 years has gradually become a real option, although impediments currently remain (Van Solinge and Henkens 2007), and current plans for reforms imply that sooner or later, the state pension eligibility age and the normal retirement age will shift from age 65 to 67; the main disagreement now seems to be on when this will happen, not whether it will happen or not. This makes it particularly interesting to analyze how different socio-economic groups forecast the future of the Dutch pension system and whether and how these forecasts have changed under the influence of the public discussion and the financial and economic crisis.

Subjective beliefs are important for economic modelling, since they make it possible to test assumptions on expectation formation like rational expectations, and, if necessary, replace them by an expectation formation model that is supported by the subjective beliefs data. In our sample, at each given point in time, all respondents are asked to predict the same outcome and in principle have access to the same information. The large heterogeneity in reported expectations in our data reveals that in spite of this, they do not have the same subjective distributions. One of the explanations for this could be that some groups lack the proper cognitive skills or are not willing to invest time to form their beliefs. Moreover, it is of interest to analyze to what extent reported beliefs are explained by observable respondent characteristics or contain additional information at the individual level.

Misguided expectations may have a negative impact on future well-being of vulnerable groups in society (see, for example, Rohwedder and van Soest 2006). In particular, overly optimistic beliefs may lead to under-saving. A recent study (De Grip et al. 2012) even suggests that there is also a direct effect of expectations on well-being (implying that the effect of overly optimistic beliefs on life-time well-being is not unambiguously negative.) 
It is therefore important to see whether different socio-economic groups have realistic views of the future or not. This is not only useful for economists concerned with the mechanisms behind the formation of beliefs but could also offer policy makers new ways of designing effective solutions to prevent saving inadequacy among specific population groups.

Since May 2006, monthly survey data were collected on the expectations of Dutch households concerning occupational pensions, old age social security, and the average retirement age ten or twenty years from the time of the interview. A subset of these data was analyzed by Van der Wiel (2008) who focused on the relation between old age social security expectations and savings decisions and Van der Wiel (2009) who investigated the effect of the number of newspaper articles on the volatility of old age social security expectations. We will not only analyze social security but also occupational pension and average retirement age expectations reported from June 2006 until June 2012. We will investigate how they have changed over time, in particular, since the onset of the financial and economic crisis, and how they vary with socio-economic characteristics.

The remainder of this paper is organized as follows. In the next section we describe the sample design and the expectations questions. After that we discuss time trends and age patterns in pension expectations, describing how the answers vary over time and how this relates to the public policy debate in the Netherlands. In the Section titled Empirical models of beliefs, we analyze some empirical models relating pension expectations to background characteristics. The final section concludes.

\section{Sample design and survey questions}

The survey was administered to members of the CentERpanel, an ongoing Internet panel managed by CentERdata, a data collection and applied research institute affiliated with Tilburg University. The sample is based upon a simple random sample from the population in the Netherlands of ages 16 and older and consists of over 2000 households in which one or more adults are invited to complete questionnaires at home every weekend over the Internet. Households without Internet access are given access by CentERdata so that the survey also covers households without Internet or without a personal computer. About $75 \%$ of all panel members respond to the questions in a given weekend. Rich background information about the panel respondents is available from previous interviews. ${ }^{1}$

Each respondent answers the questions to the specific survey on pension expectations once every three months. The total sample of respondents of ages 25 and older was randomly split into three subsamples of about the same size. One subsample gets the questions in January, April, July and October; the second subsample in February, May, August and November, etc. This implies that there are observations for one third of the sample in each month except in May and June 2006 (the first two months of the survey) when everyone was invited to participate instead of one third.

In addition to the questions on future expectations that we will analyze, the survey asks questions on other pension related issues, such as the respondents' satisfaction with several aspects of their pension provisions and the pension system in general; see De Bresser and van Soest (2009). 
The expectations questions have been asked in the form of subjective probabilities. According to Manski (2004), this is a much better way to elicit information on people's subjective distributions of future outcomes, providing more information than, for example, simple point expectations. Subjective probability questions have been extensively used and validated in US surveys, particularly the Health and Retirement Study, which has subjective probability questions on many different topics, including the future employment status, length of life, and future inheritances and bequests (Juster and Suzman 1995; Hurd 2009).

The first questions are about old age social security benefit levels (AOW: Algemene Ouderdoms Wet). According to the current system, everyone who has been a resident in the Netherlands from age 15 to age 65 is fully eligible for these benefits. The amount is determined by the official minimum subsistence level ${ }^{2}$ and depends on partnership status but usually not on earnings or employment history. There is one exception that may matter for expectations: if one spouse is older than 65 and the other is younger than 65 , the couple receives the amount for singles if the younger spouse has a paid job, but the full amount for the couple if the younger spouse does not do any paid work; the additional amount received in the latter case is called the "partner allowance". It will be abolished in 2015, and this has been announced long before the start of our survey in 2006. Respondents who are aware of this announced reform may incorporate it in their expectations concerning future benefit levels. The wording of the first series of questions was:

What do you think is the probability that 10/20 years from now the purchasing power of $A O W$ benefits will on average be

- Less than now?

- At least 10 percent less than now?

- More than now?

- At least 10 percent more than now?

Please answer on a scale from 0 to 100 percent, where 0 means it will definitely not happen and 100 means it will certainly happen.

Half of the sample got the questions with 10 years from now; the other half with 20 years from now, with randomized assignment. ${ }^{3}$ All answers from 0 to 100 were allowed for; consistency restrictions (e.g., second answer larger than the first one) were not imposed and were indeed sometimes violated by the respondents. Note that the first and third answer may well add up to less than 100 since people may attach a positive probability to the event that purchasing power remains the same. This applies in particular to the purchasing power of AOW benefits since, in the current system, they are fixed at the minimum subsistence level and reforms proposed until now do not change that (though for couples to whom the "Partner allowance" applies, the purchasing power of the total benefit will decrease in 2015 - see above).

The second set of questions concerns the purchasing power of second pillar pensions. Essentially all employees in the Netherlands participate in mandatory pension schemes organized at the firm or industry level, which guarantees them a defined benefit occupational pension that increases with their earnings. There are differences across firms and 
industries in how the pension level varies with the pattern of life cycle earnings or whether pension benefits keep track with inflation. The wording of the questions was similar to that for AOW benefits:

What do you think is the probability that 10/20 years from now the average purchasing power of occupational pensions will be

- Less than now?

- At least 10 percent less than now?

- More than now?

- At least 10 percent more than now?

Please answer on a scale from 0 to 100 percent, where 0 means it will definitely not happen and 100 means it will certainly happen.

The answers to these questions may be affected by the problems faced by occupational pension funds due to the financial crisis. Many pension funds have experienced a reduction of the accumulated pension wealth of their clients due to falling stock prices, and in response have announced that they will not compensate pension amounts for inflation in the near future. In the long run, this may lead to much lower pension levels in real (purchasing power) terms. Implicitly, the respondents are asked to forecast how much of the inflation in the next ten or twenty years will not be compensated by increases in nominal pensions - admittedly not an easy task.

The third set of questions is about the eligibility age for old age social security benefits:

What do you think is the probability that 10/20 years from now the age at which people are entitled to $A O W$ benefits will on average be

- Higher than now?

- At least two years higher than now?

- Lower than now?

- At least two years lower than now?

Please answer on a scale from 0 to 100 percent, where 0 means it will definitely not happen and 100 means it will certainly happen.

This question touches the core of the Dutch policy discussion starting in 2008 and still continuing in 2012, which focuses on raising the eligibility age for AOW benefits from 65 to 66 or 67 for cohorts that will reach age 65 after a certain date this date is also part of the discussion. The plan launched in September 2009 was to implement the changes 10 years from now, not affecting those who are currently older than 55; this plan was not implemented because the government stepped down but a similar scheme was implemented later by the new government. Current plans of the provisional government involve raising the eligibility age already earlier, that is, also for older cohorts. How this will be implemented and whether special arrangements will be made for specific occupations involving heavy physical effort is not yet clear. 
The final set of questions we will analyze refers to the retirement age. ${ }^{4}$ The wording of the questions about the retirement age is:

What do you think is the probability that 10/20 years from now the age at which people stop working will on average be

- Higher than now?

- At least two years higher than now?

- Lower than now?

- At least two years lower than now?

Please answer on a scale from 0 to 100 percent, where 0 means it will definitely not happen and 100 means it will certainly happen.

Although the current policy debate is more about postponing AOW benefits than about fixing the retirement age, the common view is that postponing entitlement to AOW benefits from age 65 to 67 will lead to the same change in the normal retirement age. Earlier retirement will remain possible, but with a pension level that is lowered in an actuarially neutral way.

\section{Time trends and age patterns in pension expectations}

During the time period covered by our data, there have been several lively policy debates on public and private pension reforms. Long before the financial and economic crisis, policy makers already saw the need to reform the public pension system due to the ageing of the population (see, for example, Bovenberg and Gradus, 2008). The rising government budget deficit during the crisis starting in 2008 has strengthened the need for reforms of state pensions, but, partly due to the resignation of the government in early 2010 and the long time it took to form a new government, final decisions have been postponed. Because the government fell, final decisions have not yet been taken in July 2012. Occupational pension funds, confronted with negative returns on their investments in the stock market (and low interest rates reducing projected coverage ratios), have emphasized the need to reduce the generosity of pension benefits, involving lower benefits or later retirement, to avoid pension premiums continuing to rise. In this section, we investigate how the general public's expectations of the generosity of the pension system have changed during the time period 2006 - 2012 and to what extent they have responded to the policy discussion.

Figure 1 shows how the average answers to the probability questions on the purchasing power of AOW benefits have developed over the time period covered by the survey (May 2006 - June 2012). ${ }^{5}$ Before discussing the time patterns, some other findings are worth noting. First, the average probabilities are consistent, in the sense that the first probability ("less than now") always exceeds the second one ("at least 10\% less than now"), the third probability ("more than now") always exceeds the fourth one ("at least 10\% more"), and the sum of the first and third probability is always much less than $100 \%$, implying that, on average, a substantial positive probability of about $30 \%$ is attached to the event that the purchasing power of AOW benefits will not change. This is in line with the notion that receiving AOW benefits should only put household income on the official poverty line, giving a fixed purchasing power level over time. 


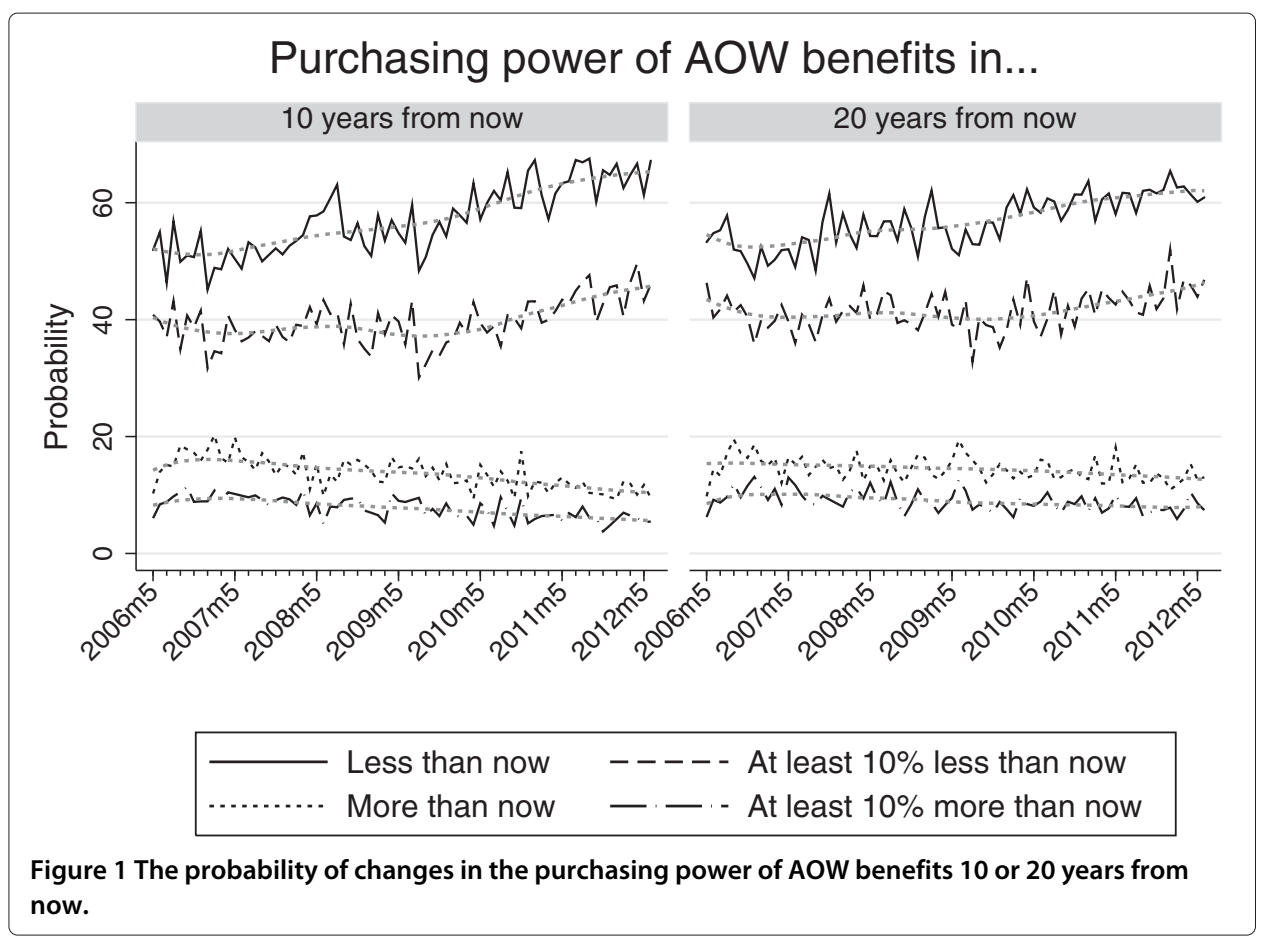

Second, the figures are asymmetric, revealing a general sense of "pessimism": the average probability that purchasing power will fall is much larger than the probability that it will rise; and the average probability that purchasing power will fall by at least $10 \%$ is much larger than the probability that it will rise by at least $10 \%$. This may seem surprising since there are no explicit plans to change the purchasing power of these benefits, which, as explained above, are in principle determined by the official poverty line. It might imply that respondents expect that the benefit level will not be fully indexed so that nominal increases will not be given at all or will not be enough to compensate for inflation. This implicitly reduces the official poverty line in real terms. In the past, there have also been time periods in which the nominal amounts of these and other social benefits were kept constant, reducing their purchasing power. The pessimistic expectations might also reflect that some respondents are aware of the future removal of the "Partner allowance", which, although applying to a limited subgroup of elderly couples only, will reduce the average benefit per person or per household.

Third, there seem to be no systematic differences between the "10 years from now" and the "20 years from now" probabilities, although there are some non-negligible differences in specific months. Perhaps most respondents see 10 or 20 years simply as in the long run and do not make any distinction.

Figure 1 does not show a strong time trend in the probabilities of an increase, an increase by $10 \%$ or more, or a fall by $10 \%$ or more until mid 2010 . This may reflect the fact that the policy debate does not directly concern the level of AOW benefits (the decision to remove the "Partner allowance" was already made in 1995), only the eligibility age. On the other hand, a somewhat stronger time trend is found for the probability that benefits will fall in real terms, although even here, the pattern is not completely consistent and somewhat different for the 10 and 20 years groups. After mid 2010, the probabilities of a fall and of a fall of at least $10 \%$ both increased. Perhaps this is when people started 
to realize that reform plans also included the possibility to claim lower AOW benefits at an earlier age, or that during times of crisis and government deficits, inflation will not be fully compensated for. Overall, we can conclude that pessimism has increased since the beginning of 2008 and particularly since mid 2010.

Figure 2 shows the average answers to the probability questions on occupational pension levels, separately for the groups who got the " 10 years from now" and the " 20 years from now" questions. We find the same asymmetry revealing a general sense of pessimism. This is less surprising than for the state benefits, since the debate on keeping the pension system sustainable in spite of the ageing of the population was already quite active in 2006.

The trend towards larger pessimism is considerably stronger here than in the expectations concerning AOW benefits. Tax reforms such as abolishing the preferential tax treatment of many early retirement arrangements (announced in 2005 and implemented in 2006) may justify increasing pessimism in 2006-2007. Since the financial and economic crisis, many pension funds have decided not to compensate their clients for inflation and recently some of them have even announced that they have to lower nominal amounts, which may well explain the increasing pessimism in the second half of the period. As before, there are no systematic differences between the 10 and 20 years groups.

Figure 3 shows how expectations concerning the eligibility age for state benefits changed over time. Here the asymmetry is even larger than for the pension and AOW benefit levels. The average reported probability that the eligibility age will fall (or will fall by at least 2 years) is quite small and might be upward biased by reporting errors of respondents who did not understand the questions or did not answer them seriously. The average reported probability that the eligibility age will increase over the next ten years was already about $60 \%$ in May 2006, rose to about 70\% in the Summer of 2009 and to about

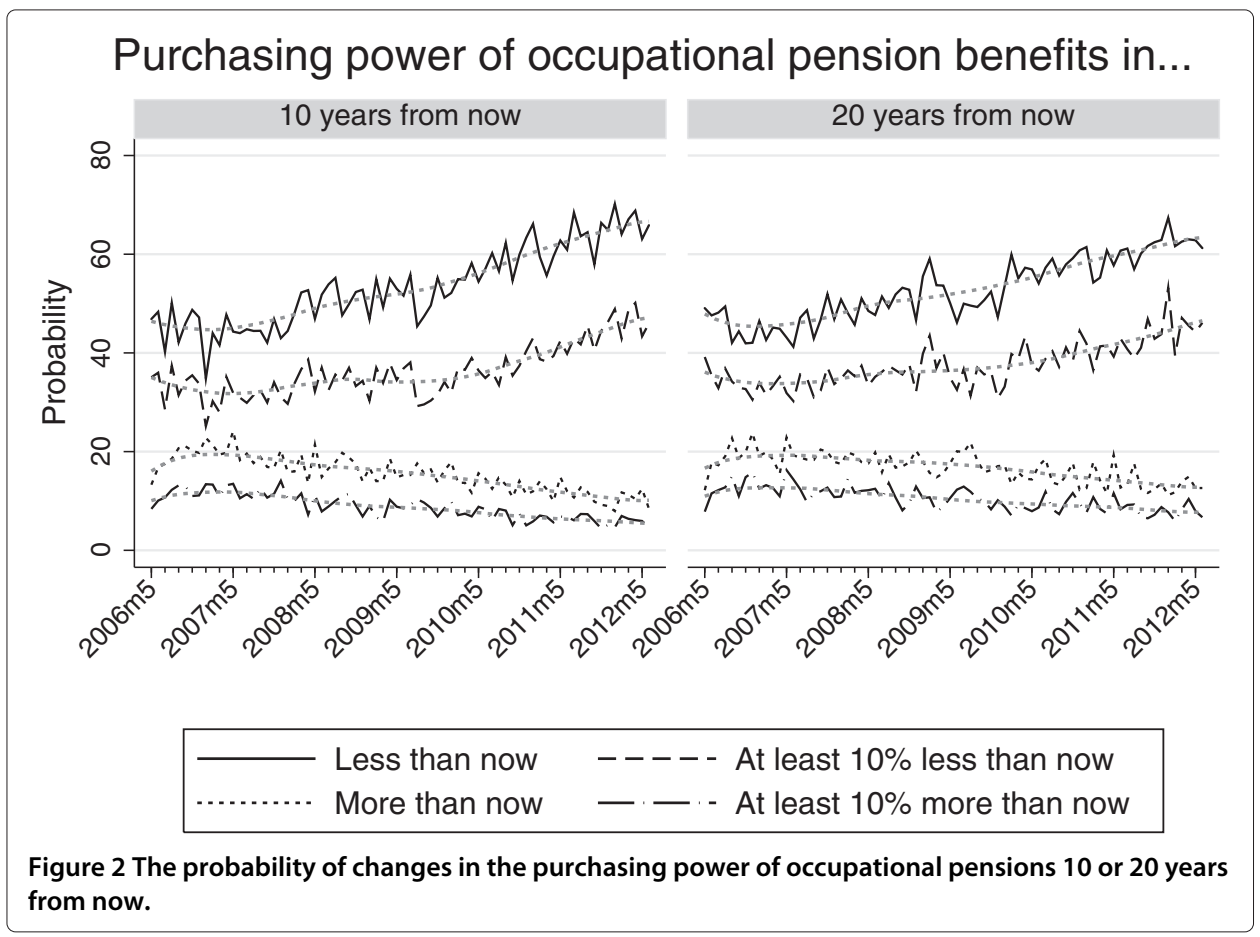




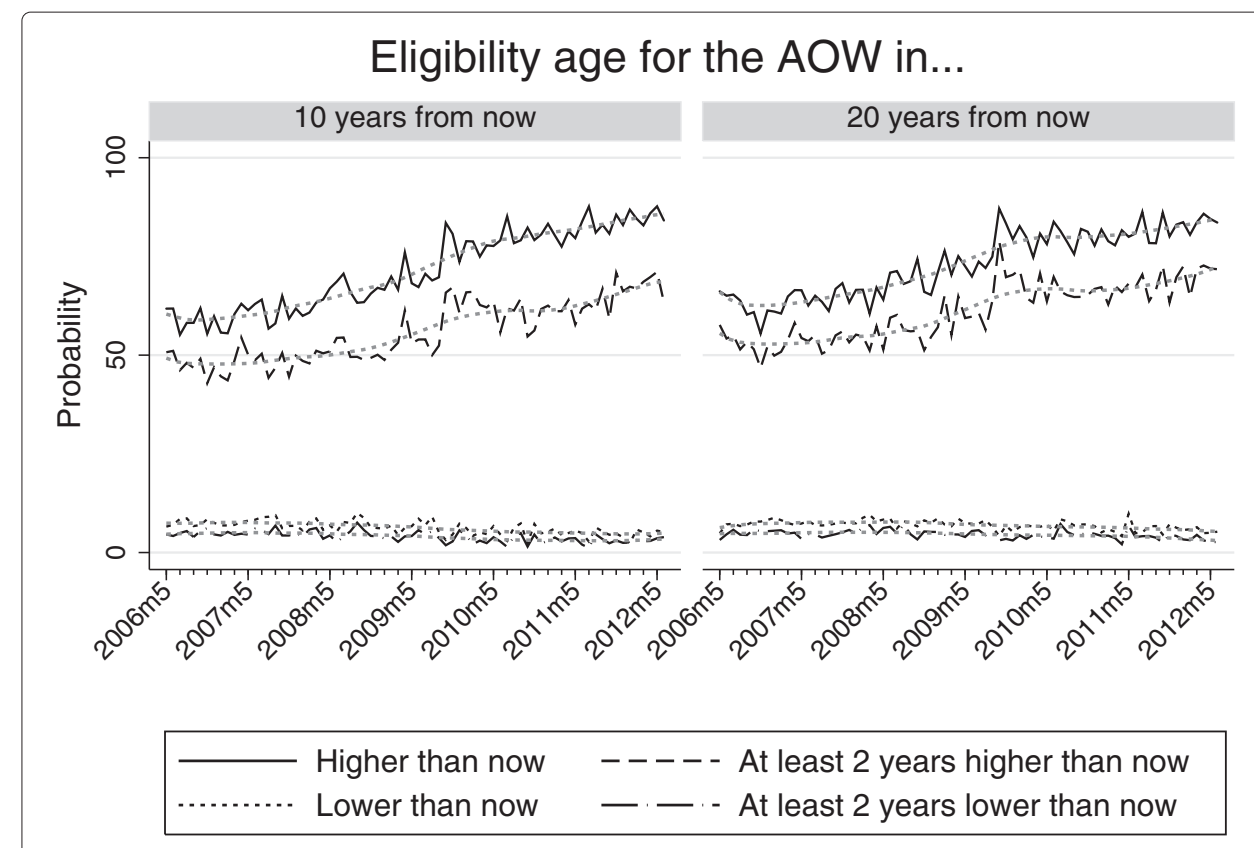

Figure 3 The probability of changes in eligibility age for AOW benefits 10 or 20 years from now.

80\% in Spring 2012. A similar clear trend towards more pessimism can be observed for the "20 years from now" group. The trend is quite plausible and in line with the announced reforms.

The figures also reveal that respondents were relatively pessimistic in the first few months of the survey (May and June 2006). One explanation is the fact that the government largely abolished preferential tax treatment of early retirement benefits in early 2006. Another reason may be that the Social Democrats announced their intention to reduce the eligibility or generosity of AOW benefits to cope with the increasing costs due to population ageing. In the months after that, these plans were weakened and other parties expressed disagreement, which is probably why respondents became less pessimistic over the summer of 2006. Respondents' optimism rose until the general elections in November 2006. Shortly after that, several groups revitalized the discussion on increasing the AOW eligibility age and labour force participation of older workers, and pessimism increased. Particularly since late 2008 , influenced by the budget problems caused by the crisis, government plans to change the AOW eligibility age took concrete form, and increasing pessimism seems perfectly justified.

Figure 4 shows the development over time of expectations concerning the average age at which people will stop working 10 or 20 years from now. The asymmetry is similar to that for the AOW eligibility age. The average reported probability that the retirement age will increase over the next ten years rises from about $60 \%$ to almost $80 \%$ between 2006 and 2012. The trend is similar but somewhat less salient for the "20 years from now" group. The probability that in the next ten or twenty years the retirement age will rise by two or more years increases less, from about $50 \%$ to about $60 \%$ for the ten years case.

The patterns in 2006 are similar to those in Figure 3. People are pessimistic at first (Summer 2006) but pessimism falls until the general elections in November. In the first 


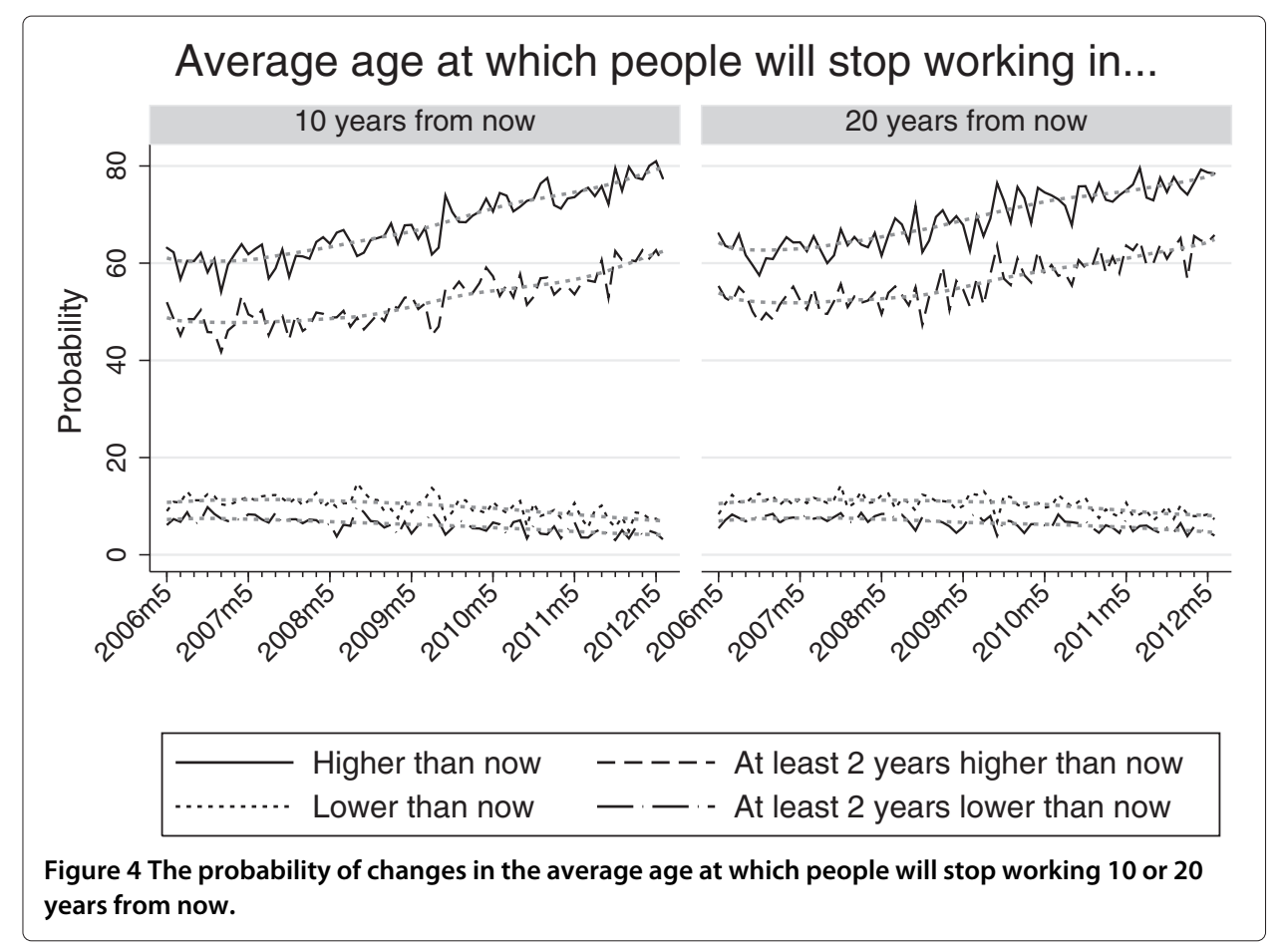

few months of 2007, the new government launched a plan to stimulate labour force participation of older workers by making AOW benefits dependent on participation in the years before the normal retirement age. In response to this, the number of respondents expecting an increase in the average retirement age rose. The effect disappeared when the government plans appeared to be unfeasible. In spring 2008 the expected average retirement age rose again, possibly because some respondents already feared that the financial crisis would affect the accumulated pension wealth invested by pension funds. Respondents' expectations then remained approximately constant until the summer of 2009, but pessimism increased during the more recent period (Fall 2009 - Spring 2012).

The probability questions ask about general events and if everyone would have the same information set and the same way of forming their subjective distributions (like rational expectations), there should be no systematic association with respondent characteristics. We will analyze this for a large set of individual characteristics in multivariate regressions in the next section. Here we present the relation between the probabilities concerning changing the eligibility age for state benefits (see Figure 3) with gender (Figure 5) and age (Figure 6). Figure 5 shows the time pattern for men and women separately. The trend is almost identical for men and women. In most time periods, the two curves on the probabilities of postponing eligibility suggest that men are somewhat less pessimistic than women, but the differences are small.

Figure 6 shows how the subjective probabilities vary with respondent age, combining data from all available time periods. ${ }^{6}$ These figures show that pessimism concerning the state pension eligibility age falls with age. For example, the average percentage probability that the state pension eligibility age will be increased is about $60 \%$ for respondents of 30 years old, but only about $40 \%$ for respondents aged 70 . The average probability that the same eligibility age will rise by at least two years is about $40 \%$ for the youngest group 

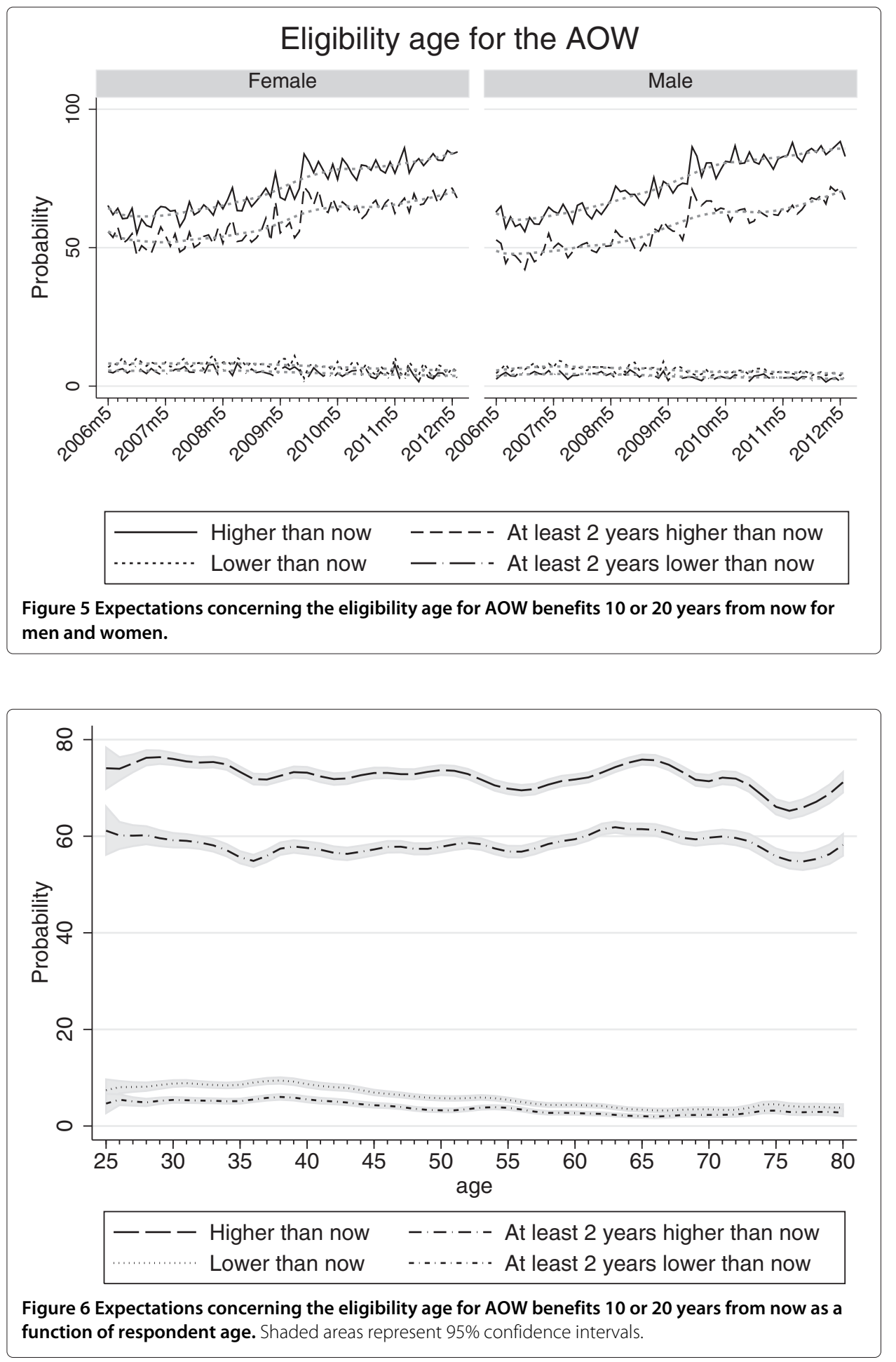

and only $25 \%$ for the oldest age group. A similar age pattern is found for the other questions (results available upon request from the authors) and the age patterns seem even stronger than the time trends discussed above. Interpreting the age patterns in terms of general optimism or pessimism about the future of the pension system, these results suggest the opposite of those of Dominitz and Manski (2005), who find that young people 
have more optimistic expectations on equity returns than older people. There may also be alternative explanations than age or cohort differences in optimism and pessimism for some of the age patterns. For example, different age groups have different consumption patterns. If expected price changes are heterogeneous across consumption commodities, this may induce differences in which nominal amounts the various age groups think are necessary to maintain purchasing power. Moreover, there are age and cohort differences in home ownership rates and the type and amount of mortgage people hold, and expectations concerning policy reforms in the housing market such as limiting tax deductability of mortgage interest payments may affect different age groups in different ways. For example, older people are often renting or have already redeemed most of their mortgage, so that they may not incorporate the consequences of less generous tax treatment of mortgages for the purchasing power of future retirement income.

\section{Empirical models of beliefs}

In this section, we will assess the impact of respondents' demographic characteristics on their reported retirement expectations. We are interested in knowing if some groups in society are particularity pessimistic or display unwarranted optimism toward retirement. As emphasized in Section Introduction, there are several reasons why we think this is important: to test the rational expectations hypothesis and to determine the usefulness of collecting this type of information at the micro level in future surveys, and to analyze the potential negative impact of misguided perceptions of the future on well-being for vulnerable groups in society, in particular through "under-saving."

\subsection{Model specification}

From now on we focus our attention on the questions concerning negative outcomes, since given the current situation of pensions, the negative changes seem more relevant than changes that would increase the cost of the pension system (as confirmed by the rather low value for the "optimistic" probabilities in the previous section). We model eight dependent variables: the answers to the questions concerning any decrease or a decrease of more than $10 \%$ in the generosity of the old age social security benefits (AOW) and of occupational pensions, and the answers to questions concerning any increase or an increase of at least two years in the age of eligibility to AOW benefits and of the average retirement age in the Netherlands.

All dependent variables are subjective probabilities and take values between $0 \%$ points and $100 \%$-points, and a substantial number of respondents used these extremes: the percentage of zeros varies from $2.2 \%$ to $11.9 \%$, and the fraction of $100 \%$ answers varies from $4.6 \%$ to $22.5 \%$. We take into account the censored nature of the variables in our estimations by estimating two-limit Tobit specifications. ${ }^{7}$ Eight separate models are used for each of the probability questions concerning the more pessimistic outcomes (levels of state and occupational pensions lower or at least $10 \%$ lower; eligibility age for state pensions and average retirement age delayed or delayed by at least two years).

Over time, all respondents were asked to answer the questions up to 15 times, allowing us to control for unobserved heterogeneity at the respondent level, using panel data techniques. We therefore use random-effects models. ${ }^{8}$ This gives the following model specification (with separate models for each of the eight probabilities): 


$$
\begin{aligned}
P_{i t}^{*}=x_{i t}^{\prime} \beta+\alpha_{i}+\epsilon_{i t} & \begin{cases}0 & \text { if } P_{i t}^{*} \leq 0 \\
P_{i t}^{*} & \text { if } 0<P_{i t}^{*}<100 \\
100 & \text { if } P_{i t}^{*} \geq 100\end{cases} \\
\alpha_{i} \mid x_{i 1}, \ldots, x_{i T} & \sim N\left(0, \sigma_{\alpha}^{2}\right) \\
\epsilon_{i t} \mid x_{i 1}, \ldots, x_{i T}, \alpha_{i} & \sim \text { iid } N\left(0, \sigma_{\epsilon}^{2}\right)
\end{aligned}
$$

Here $P_{i t}^{*}$ is a latent variable, determined by a vector of explanatory variables $x_{i t}$, an unobserved individual effect $\alpha_{i}$ and an idiosyncratic error term $\epsilon_{i t}$. The observed probability $P_{i t}$ is obtained from $P_{i t}^{*}$ through censoring at both ends, implying positive probabilities of reporting 0 and 100. The individual effects and error terms are assumed to follow normal distributions independent of the $x_{i t}$, as in the standard random effects Tobit model. The model parameters $\left(\beta, \sigma_{\alpha}\right.$ and $\left.\sigma_{\epsilon}\right)$ are estimated jointly using maximum likelihood. Estimates are obtained using Stata.

The same independent variables $x_{i t}$ were included in all eight models. First, we include a set of basic demographic and socio-economic respondent and household characteristics: a dummy variable with value 1 if the respondent is a male, age of the respondent, age squared, a dummy taking the value 1 if the respondent lives with a partner. We control for education using dummies for intermediate education (secondary general or intermediate vocational) and high education (higher vocational or university), using low education (primary school only or lower vocational schooling) as the benchmark. To capture employment status, we include dummy variables for respondents who are retired, disabled (or partially disabled), unemployed, or homemaker. For workers, we distinguish between the private and the public sectors, where the latter includes health, education, and civil servants. ${ }^{9}$ We included time dummies for each month (except one) in order to control for macro-economic shocks on beliefs, like the financial and economic crisis. We also included a dummy variable that takes the value 0 if the question concerned a 10-year horizon and value 1 if it concerned a 20 -year horizon.

We controlled for respondents' income by including their personal log-income as an explanatory variable. Respondents who reported an income larger than $€ 8,000$ per month were considered as outliers and removed from the sample. We also included in the model respondents who explicitly refused to answer the income questions or who reported a value of 0 , which may mask non-response. For these cases the value of log-income was set to 0 ; dummy variables were added reporting zero income and for (explicit) non-response.

In Table 1, we present the mean values of the explanatory variables in the first month (May 2006) and in the spring of 2012 (when one third participated each month, so that the last three months together cover the complete sample). The table shows that the means of most of the variables are quite stable over time. We also see that very few respondents did not report an income (none in the first month, 10 in the last three months). Not all respondents always answered the questions, due to refreshment, attrition, or temporary non-participation (e.g., holidays). About 1,300 respondents answered in the first month and in the last three months, but in total, about 3,810 respondents who took part in the survey over time were included in the estimation of each equation. Average age is relatively high, because all respondents of age 25 and older are asked to answer the questions (with no upper age limit). Median net personal income (zeroes excluded) rises from 
Table 1 Means of the explanatory variables in May 2006 and April-June 2012

\begin{tabular}{lcc}
\hline & May & April-June \\
\hline Male & $\mathbf{2 0 0 6}$ & $\mathbf{2 0 1 2}$ \\
Partner & 0.496 & 0.488 \\
Age & 0.768 & 0.790 \\
Log. net-inc. (if inc. > 0) & 49.992 & 50.562 \\
Inc. = 0 & 7.165 & 6.452 \\
Unk. Inc. & 0.108 & 0.092 \\
Educ. Med. & 0.024 & 0.017 \\
Educ. High & 0.389 & 0.412 \\
Self-employed & 0.234 & 0.252 \\
Retired & 0.035 & 0.061 \\
Disabled & 0.202 & 0.195 \\
Homemaker & 0.052 & 0.041 \\
Unemployed & 0.163 & 0.108 \\
Public sector & 0.020 & 0.029 \\
Home owner & 0.212 & 0.255 \\
In 20 years & 0.680 & 0.755 \\
\hline$N$ & 0.512 & 0.510 \\
\hline Note:Means use & 1,309 & 1,693 \\
\hline
\end{tabular}

Note: Means use respondents included in at least one of the regressions; means are weighted with sample weights based upon age, gender and education.

$€ 1,500$ in the first month to about $€ 1,750$ at the end of the survey period; there is no correction for inflation. The average education level also increases over time. The fraction of homemakers falls over time, while the number of public sector employees rises. A large fraction of all workers (almost 20\%) are in the public sector, which is defined in a broad sense, including, for example, the (semi-public) health and education sectors. The home ownership rises substantially between the two time periods, in line with the rising trend in the Netherlands over the past twenty years. The dummy "In 20 years" has value 1 if the questions referred to 20 years from now and 0 otherwise; the time period in the questions was randomly drawn, independent of all other variables and with equal probabilities for " 10 years" and " 20 years" so that by design its ex ante mean should be equal to 0.5 . The ex post mean is somewhat different, mainly due to non-response.

\subsection{Estimation results}

The estimation results are presented in Tables 2 and $3 .{ }^{10}$ Since we estimated the equations separately, we do not consider the correlations between the error terms or between the unobserved heterogeneity terms of the different equations. We consider a 5\%-significance level in discussing which variables are significant and insignificant. Note that the models all explain the subjective probability of a negative outcome, so a positive sign in the estimates indicates an increase in pessimism if the independent variable increases. ${ }^{11}$

The results vary across the eight probabilities, but we observe some common patterns. First, men report significantly lower probabilities when it comes to the four worst-case scenarios, indicating that men are less pessimistic than women, in line with findings in the finance literature (Barber and Odean 2001). For example, the estimated probability that the state benefit eligibility age will rise by at least two years is more than four percentage points higher for men than for women, keeping other characteristics constant. This is a 
Table 2 Estimation results two-limit tobit models with random effects: probabilities of negative changes in future generosity of state and occupational pensions

\begin{tabular}{|c|c|c|c|c|}
\hline & \multicolumn{2}{|c|}{ Generosity of AOW } & \multicolumn{2}{|c|}{ Generosity of occupational pension } \\
\hline & Less & At least $10 \%$ less & Less & At least $10 \%$ less \\
\hline \multirow[t]{2}{*}{ Male } & -0.966 & $-4.642^{* * *}$ & -1.819 & $-4.222^{* * *}$ \\
\hline & $(-0.832)$ & $(-4.541)$ & $(-1.608)$ & $(-4.250)$ \\
\hline \multirow[t]{2}{*}{ Partner } & $2.086^{* *}$ & $2.766^{* * *}$ & 1.159 & 1.446 \\
\hline & $(1.967)$ & $(2.912)$ & $(1.127)$ & $(1.574)$ \\
\hline \multirow[t]{2}{*}{ Age } & $0.911^{* * *}$ & $0.660^{* * *}$ & 0.272 & 0.084 \\
\hline & $(4.195)$ & $(3.409)$ & $(1.286)$ & $(0.447)$ \\
\hline \multirow[t]{2}{*}{ Age-sqr./100 } & $-1.281^{* * *}$ & $-0.830^{* * *}$ & $-0.682^{* * *}$ & $-0.312^{*}$ \\
\hline & $(-6.217)$ & $(-4.517)$ & $(-3.405)$ & $(-1.752)$ \\
\hline \multirow[t]{2}{*}{ Log. net-inc. } & 1.094 & -0.170 & 0.116 & $-1.067^{*}$ \\
\hline & $(1.628)$ & $(-0.280)$ & $(0.178)$ & $(-1.821)$ \\
\hline \multirow[t]{2}{*}{$\operatorname{lnc} .=0$} & 6.320 & -1.700 & -0.570 & $-6.597^{*}$ \\
\hline & $(1.390)$ & $(-0.412)$ & $(-0.129)$ & $(-1.659)$ \\
\hline \multirow[t]{2}{*}{ Unk. Inc. } & 8.155 & 6.562 & 2.455 & -0.235 \\
\hline & $(1.514)$ & $(1.343)$ & $(0.470)$ & $(-0.050)$ \\
\hline \multirow[t]{2}{*}{ Educ. Med. } & $6.026^{* * *}$ & $1.812^{*}$ & $4.221^{* * *}$ & 0.657 \\
\hline & $(4.850)$ & (1.649) & (3.494) & $(0.616)$ \\
\hline \multirow[t]{2}{*}{ Educ. High } & $10.908^{* * *}$ & $3.910^{* * *}$ & $6.687^{* * *}$ & 1.133 \\
\hline & (8.601) & (3.498) & $(5.422)$ & $(1.044)$ \\
\hline \multirow[t]{2}{*}{ Self-employed } & 0.302 & 2.386 & -0.759 & 0.587 \\
\hline & $(0.176)$ & (1.559) & $(-0.456)$ & $(0.395)$ \\
\hline \multirow[t]{2}{*}{ Retired } & 1.421 & -1.255 & 0.238 & -1.364 \\
\hline & $(1.141)$ & $(-1.116)$ & $(0.197)$ & $(-1.254)$ \\
\hline \multirow[t]{2}{*}{ Disabled } & -0.336 & -0.387 & -1.192 & 0.739 \\
\hline & $(-0.182)$ & $(-0.232)$ & $(-0.662)$ & $(0.457)$ \\
\hline \multirow[t]{2}{*}{ Homemaker } & 0.256 & -1.907 & -0.714 & $-3.495^{* *}$ \\
\hline & $(0.163)$ & $(-1.349)$ & $(-0.468)$ & $(-2.559)$ \\
\hline \multirow[t]{2}{*}{ Unemployed } & 1.811 & 0.734 & 1.195 & 1.317 \\
\hline & (0.969) & $(0.435)$ & $(0.666)$ & $(0.814)$ \\
\hline \multirow[t]{2}{*}{ Public sector } & 1.533 & 0.183 & $2.089^{* *}$ & 0.702 \\
\hline & $(1.451)$ & (0.194) & $(2.041)$ & $(0.772)$ \\
\hline \multirow[t]{2}{*}{ Homeowner } & 1.138 & -0.877 & 0.963 & -0.788 \\
\hline & $(1.100)$ & $(-0.950)$ & $(0.960)$ & $(-0.881)$ \\
\hline \multirow[t]{2}{*}{ In 20 years } & -0.135 & $2.783^{* * *}$ & $-0.705^{* *}$ & $1.718^{* * *}$ \\
\hline & $(-0.401)$ & $(8.940)$ & $(-2.164)$ & $(5.747)$ \\
\hline \multirow[t]{2}{*}{ Constant } & $29.424^{* * *}$ & $35.836^{* * *}$ & $48.754^{* * *}$ & $50.083^{* * *}$ \\
\hline & (4.104) & $(5.573)$ & (6.990) & $(8.045)$ \\
\hline Num. Ind. & 3,806 & 3,801 & 3,807 & 3,805 \\
\hline Num. Obs. & 3,6499 & 36,328 & 36,621 & 36,593 \\
\hline$\rho$ & 0.463 & 0.424 & 0.467 & 0.432 \\
\hline$\sigma_{\alpha}$ & 27.567 & 23.843 & 26.943 & 23.297 \\
\hline$\sigma_{\varepsilon}$ & 29.696 & 27.793 & 28.795 & 26.738 \\
\hline
\end{tabular}

Dummies for each but the initial time period were included, but are not reported.

$t$-values in parentheses.

Stars denote significance: * $10 \%$ level, ** $5 \%$ level, *** $1 \%$ level.

much larger difference than the gender difference in Figure 5, where other characteristics were not controlled for.

Second, respondents with a partner have significantly more pessimistic expectations concerning generosity and eligibility age of AOW and concerning the average retirement 
Table 3 Estimation results two-limit tobit models with random effects: probabilities of delays in eligibility to AOW benefits and average retirement age

\begin{tabular}{|c|c|c|c|c|}
\hline & \multicolumn{2}{|c|}{ Eligibility to AOW } & \multicolumn{2}{|c|}{ General retirement age } \\
\hline & Later & At least 2 yrs later & Later & At least 2 yrs later \\
\hline \multirow[t]{2}{*}{ Male } & 1.080 & $-5.126^{* * *}$ & -0.031 & $-5.178^{* * *}$ \\
\hline & $(0.961)$ & $(-4.738)$ & $(-0.031)$ & $(-5.286)$ \\
\hline \multirow[t]{2}{*}{ Partner } & $2.787^{* * *}$ & $2.486^{* *}$ & $2.911^{* * *}$ & $2.516^{* * *}$ \\
\hline & $(2.717)$ & $(2.490)$ & $(3.207)$ & $(2.812)$ \\
\hline \multirow[t]{2}{*}{ Age } & $-1.149^{* * *}$ & $-0.996^{* * *}$ & -0.199 & -0.288 \\
\hline & $(-5.422)$ & $(-4.861)$ & $(-1.062)$ & $(-1.569)$ \\
\hline \multirow[t]{2}{*}{ Age-sqr./100 } & $0.901^{* * *}$ & $0.938^{* * *}$ & 0.069 & $0.299^{*}$ \\
\hline & $(4.475)$ & $(4.820)$ & $(0.389)$ & $(1.715)$ \\
\hline \multirow[t]{2}{*}{ Log. net-inc. } & $2.252^{* * *}$ & $1.619^{* *}$ & $1.730^{* * *}$ & $1.686^{* * *}$ \\
\hline & $(3.464)$ & $(2.529)$ & (3.022) & $(2.964)$ \\
\hline \multirow[t]{2}{*}{$\operatorname{lnc} .=0$} & $13.845^{* * *}$ & $10.923^{* *}$ & $12.917^{* * *}$ & $12.261^{* * *}$ \\
\hline & (3.152) & $(2.515)$ & (3.340) & (3.179) \\
\hline \multirow[t]{2}{*}{ Unk. Inc. } & $16.189^{* * *}$ & $13.261^{* * *}$ & $13.122^{* * *}$ & $14.282^{* * *}$ \\
\hline & (3.125) & $(2.588)$ & $(2.873)$ & (3.140) \\
\hline \multirow[t]{2}{*}{ Educ. Med. } & $4.218^{* * *}$ & -0.146 & $3.655^{* * *}$ & 0.189 \\
\hline & $(3.505)$ & $(-0.125)$ & $(3.402)$ & $(0.180)$ \\
\hline \multirow[t]{2}{*}{ Educ. High } & $5.262^{* * *}$ & -1.509 & $4.895^{* * *}$ & $-2.066^{*}$ \\
\hline & $(4.282)$ & $(-1.274)$ & $(4.455)$ & $(-1.930)$ \\
\hline \multirow[t]{2}{*}{ Self-employed } & 0.414 & $3.228^{* *}$ & 0.119 & 2.277 \\
\hline & $(0.248)$ & (1.980) & $(0.081)$ & $(1.570)$ \\
\hline \multirow[t]{2}{*}{ Retired } & $4.886^{* * *}$ & 1.653 & 1.627 & -0.162 \\
\hline & (3.989) & $(1.390)$ & (1.532) & $(-0.154)$ \\
\hline \multirow[t]{2}{*}{ Disabled } & -0.103 & 1.429 & $-3.742^{* *}$ & -0.904 \\
\hline & $(-0.058)$ & $(0.812)$ & $(-2.377)$ & $(-0.577)$ \\
\hline \multirow[t]{2}{*}{ Homemaker } & 1.392 & -1.191 & -2.181 & $-2.414^{*}$ \\
\hline & $(0.917)$ & $(-0.799)$ & $(-1.631)$ & $(-1.817)$ \\
\hline \multirow[t]{2}{*}{ Unemployed } & $3.103^{*}$ & 1.723 & 2.483 & $2.987^{*}$ \\
\hline & (1.738) & $(0.971)$ & (1.599) & $(1.915)$ \\
\hline \multirow[t]{2}{*}{ Public sector } & 0.321 & 0.790 & 0.078 & 0.357 \\
\hline & $(0.317)$ & $(0.797)$ & $(0.087)$ & $(0.403)$ \\
\hline \multirow[t]{2}{*}{ Homeowner } & $2.034^{* *}$ & 1.276 & 1.215 & 0.515 \\
\hline & $(2.043)$ & $(1.310)$ & $(1.371)$ & $(0.590)$ \\
\hline \multirow[t]{2}{*}{ In 20 years } & $3.864^{* * *}$ & $8.733^{* * *}$ & $2.429^{* * *}$ & $6.135^{* * *}$ \\
\hline & $(11.851)$ & (26.768) & (8.556) & (21.539) \\
\hline \multirow[t]{2}{*}{ Constant } & $74.730^{* * *}$ & $65.060^{* * *}$ & $57.091^{* * *}$ & $47.996^{* * *}$ \\
\hline & $(10.703)$ & $(9.577)$ & (9.249) & $(7.904)$ \\
\hline Num. Ind. & 3,807 & 3,806 & 3,810 & 3,810 \\
\hline Num. Obs. & 36,646 & 36,611 & 36,653 & 36,640 \\
\hline$\rho$ & 0.479 & 0.434 & 0.488 & 0.454 \\
\hline$\sigma_{\alpha}$ & 26.504 & 25.299 & 24.131 & 23.261 \\
\hline$\sigma_{\varepsilon}$ & 27.641 & 28.840 & 24.731 & 25.502 \\
\hline
\end{tabular}

Dummies for each but the initial time period were included, but are not reported. $t$-values in parentheses.

Stars denote significance: ${ }^{*} 10 \%$ level, ${ }^{* *} 5 \%$ level, *** $1 \%$ level.

age. A possible explanation is that couples are more concerned about retirement issues than singles and therefore pay more attention to the public debate. Another possible explanation could be that respondents with partners are often secondary earners working 
part-time, for whom income is not a good proxy to financial literacy or interest in financial matters (see below).

In general, high income individuals more often believe that 10 or 20 years from now, workers will retire later and the AOW eligibility age will be higher. This view corresponds with the opinion of "financially literate" individuals. The dummy with value 1 if reported income is zero or if no income is reported is also significant for the four questions concerning eligibility and retirement ages. Taking into account that in these cases the log income variable is set to zero, these estimates imply that non- and zero-reporters are not very different from those with an average log income. ${ }^{12}$

Similarly, we find that people with medium and high education report a significantly higher probability for the four more generic pessimistic questions. The effect is not significant for the four questions concerning a substantial decrease of "at least 10\%" or "more than two years". This finding is in line with the notion that pessimism is probably justified and the higher educated respondents tend to be better informed, more financially literate, and more often make plans for retirement (cf. Lusardi and Mitchell 2007).

Most of the dummies on employment status are insignificant. Retirees are particularly pessimistic concerning the age of eligibility for AOW benefits. Unemployed individuals are somewhat more pessimistic about the AOW eligibility age and the average retirement age than private sector workers (the omitted category), but the differences are only marginally significant. The coefficient on the homemaker dummy is usually negative and a few times significant, suggesting that homemakers are less pessimistic than employees in the private sector. Disability benefit recipients less often think that the retirement age will rise. Public sector workers are more pessimistic than private sector workers concerning the future purchasing power of occupational pensions.

Age generally has a significant effect and the marginal effect of age is usually negative for most of the sample. Where age is significant, the age pattern is typically decreasing over the age range in the sample ( 25 and older) so that in general, keeping other characteristics constant, younger individuals are more pessimistic concerning the pension system than older people. This is in line with the age patterns in Figure 6, where other characteristics were not kept constant. This finding cannot be explained from the knowledge or general optimism arguments that we used above. Perhaps it relates to the fact that, in spite of the fact that the questions explicitly mention "10 years from now" or "20 years from now" respondents often answer the questions thinking about their own pension provision at the time of their retirement, which will probably be less generous for younger people than for those who are already approaching retirement.

The only significant difference between home owners and renters is that home owners are more pessimistic concerning the age of AOW eligibility. This is somewhat unexpected given the argument given in the previous section that expectations concerning housing market reforms may have different consequences for the disposable income of owners and renters (see, Time trends and age patterns in pension expectations section).

Finally, there is a significant positive effect of asking questions concerning a 20-year horizon rather than a 10-year horizon, indicating that respondents are more pessimistic concerning pension provisions 20 years from now than concerning pensions 10 years from now. This could be expected from the figures in the previous section and is in line with the fact that the effect of population ageing on, for example, the ratio between the 
65+ and 65-population sizes, is expected to increase further during the next twenty years (see, for example, van Duin and Garssen 2011).

The estimates of the standard deviations at the bottom of the table ( $\sigma_{\alpha}$ for the individual effects; $\sigma_{\epsilon}$ for the error terms) indicate that there is substantial unobserved heterogeneity: between 40 and 50 percent of the total unexplained variation in the reported probabilities can be ascribed to time persistent individual effects (as indicated by $\rho=\sigma_{\alpha}^{2} /\left(\sigma_{\alpha}^{2}+\sigma_{\epsilon}^{2}\right)$ ). This also answers the second question we raised at the beginning of this section: the covariates used in our model do not capture the heterogeneity in beliefs completely, and the reported probabilities provide additional information - if they would just add noise, we would expect $\sigma_{\alpha}$ to be small compared to $\sigma_{\epsilon}$. This is in line with the existing literature emphasizing the value of subjective probabilities in survey data (see, e.g., Manski 2004), reinforcing the idea that eliciting information of expectations is important for researchers interested in questions related to retirement and pensions.

\section{Conclusion}

We have analyzed expectations of the Dutch population of ages 25 and older concerning the system of income provision after retirement. The recent trends and policy discussions that seem to justify the expectation that future pensions will be less generous in terms of pension levels, eligibility ages, or both, are reflected in the trend in expectations, but only to a limited extent. For example, during our observation window from Summer 2006 to Spring 2012 it has become very likely that AOW eligibility will be postponed from age 65 to age 67 at some stage in the next 20 years. Accordingly, the average probability that this age will rise by at least two years has gradually risen from about $50 \%$ to about $70 \%$ only. Expectations seem to adjust only gradually to the new reality and as a consequence, average pension system expectations of the Dutch population have probably been too optimistic during the past few years. Our micro-data also revealed substantial heterogeneity across and within socio-economic groups, suggesting that the average optimism is due to the "over-optimism" of a substantial subsample, whereas others may well have rational expectations.

The finding that men are less pessimistic than women is consistent with findings in existing studies in a different context. The fact that richer (and higher educated) individuals are significantly more pessimistic concerning some aspects of retirement than poorer respondents is in line with a positive association between socio-economic status and knowledge of the public debate on pension provisions. The finding that younger individuals are more pessimistic than older respondents may relate to the fact that respondents often answer the questions thinking about their own pension provision at the time when they retire (in spite of the wording of the questions).

From an economic policy point of view, the results we have obtained in models that relate expectations to socio-economic characteristics contain both good and bad news, under the assumption that pessimism is justified and the more pessimistic respondents are also the most realistic. That younger individuals are aware of the possible negative changes in pensions is certainly comforting news, as long as they will adapt their saving behaviour accordingly. The younger individuals, who are likely to witness changes to the pension system, have time and room to adapt their employment career and their lifecycle saving plans to this new reality, and can minimize an unwanted decline of well-being at retirement. 
On the other hand, we view the fact that poorer individuals tend to be more optimistic as bad news. The poorer individuals depend more on the old age social security benefits than their richer counterparts, and are therefore more affected by a reduction in the generosity of these benefits. For the poorest among them, it might not make a lot of difference to anticipate the changes, as they are not able to save for retirement and their income will probably consist almost solely of social security anyhow. However, not anticipating the policy changes could have a larger negative impact on the well-being of the middle class, who are likely to save too little under erroneous beliefs concerning the future. An unrealistic view of the future of public pensions could have important welfare effects for these respondents.

Future research opportunities remain. Adding more waves of data will help to better identify the long term consequences of the financial and economic crisis. It also seems interesting to analyze whether these expectations are associated with current decisions on, for example, retirement savings. In addition, some methodological improvements are possible. First, we already mentioned that the full information on individual behaviour provided by the multidimensional panel structure is not fully exploited. We could control for general pessimism by estimating the equations jointly, and by allowing the terms of individual heterogeneity to be correlated among individuals. Another interesting step would be to jointly analyze the beliefs of respondents within a household, and to assess if unwarranted optimism or pessimism is contagious among partners. Finally, since respondents tend to answer our probability questions using focal answers such as " 50 percent," the assumptions needed for the Tobit model may not be justified, and it seems worthwhile to check whether results are robust using a more general model that explicitly accounts for rounding and focal points like 50-50 answers.

\section{Endnotes}

${ }^{1}$ See http://www.centerdata.nl/en/TopMenu/Wat_doen_we/Dataverzameling/CentERpanel/ index.html and http://www.centerdata.nl/en/TopMenu/Projecten/DNB_household_study/.

${ }^{2}$ The January 2012 amounts (before taxes and including vacation allowance) are $€ 1,107$ for singles and $€ 1,524$ for couples.

${ }^{3}$ This randomization was independent across waves, so the same person could get the questions with 10 years in one wave and with 20 years in another wave; in a given wave, all questions for a given respondent had 10 years, or they all had 20 years.

${ }^{4}$ We did not feel it was useful to ask about the eligibility age for occupational pensions, because with increasing flexibility and actuarially fair choices, the formal eligibility age can be quite low but with unattractively low pension benefits this is not very meaningful.

${ }^{5}$ The figures are weighted with sample weights to correct for unit non-response related to gender, age, and education.

${ }^{6}$ Estimations obtained using local linear regression with Gaussian kernel and a bandwidth of 2 years.

${ }^{7}$ We do not address the issue of possible focal answers (see, e.g., Fischhoff and Bruine de Bruin 1999, or Hudomiet et al. 2011), since heaping at 0,50 or 100 does not seem such a large problem in these data, with the percentage of 50-50 answers varying between 12 and 17 percent.

${ }^{8}$ Since many socioeconomic characteristics (education, gender) hardly vary over time we did not pursue using fixed effects models. 
${ }^{9}$ We also estimated specifications with dummies for different parts of the private sector (manufacturing, construction, trade and transport, financial industry, other services) but found almost all of these were insignificant.

${ }^{10}$ Time dummies are included but their coefficients are not reported, since their pattern very much resembles the time trends in Figures 1, 2, 3 and 4.

${ }^{11}$ The estimates of the slope coefficients cannot be interpreted as marginal effects on the expected subjective probabilities, due to the non-linearity of the model. The marginal effect of a covariate is equal to the estimated parameter times the probability of being uncensored; for the average respondent, this probability varies from 0.747 to 0.865 over the eight questions.

${ }^{12}$ The average log income is about 7.25 , so the coefficients on the dummies should be compared with 7.25 times the coefficient on log income.

\title{
Competing interests
}

The IZA Journal of European Labor Studies is committed to the IZA Guiding Principles of Research Integrity. The authors declare that they have observed these principles.

\section{Acknowledgments}

This research was funded by Stichting Instituut GAK and Netspar. We are grateful to Jan Nelissen, Rob Alessie, Viola Angelini, Charles Bellemare, Mauro Mastrogiacomo, Pierre-Carl Michaud, Martin Salm, Karen van der Wiel, an anonymous referee, and to the participants of the conferences "Labour force participation and the well-being of the 50+ population" in Utrecht, September 2009 and "International Pension Workshop" in Zurich, June 2010.

Responsible Editor: Sara de la Rica

\author{
Author details \\ ${ }^{1}$ Netspar and CIRPÉE, Université Laval, Pavillon J.-A.-DeSève, Québec, QC, Canada, G1V OA6. ${ }^{2}$ Netspar, Tilburg University, \\ Warandelaan 2, 5037 AB Tilburg, The Netherlands.
}

Received: 26 March 2012 Accepted: 24 July 2012

Published: 9 October 2012

\section{References}

Barber BM, Odean T (2001) Boys will be boys: gender, overconfidence and common stock investment. Q J Econ 116(1): 261-292

Bellemare C, Manski CF (2011) Introduction 'measurement and analysis of subjective expectations'. J Appl Econom 26(3): 351

Benítez-Silva H, Dwyer DS (2005) The rationality of retirement expectations and the role of new information. Rev Econ Stat 87(3): 587-592

Bovenberg AL, Gradus RHJM (2008) Dutch policies towards ageing. Eur View 7(2): 265-275

Chan S, Stevens AH (2008) What you don't know can't help you: pension knowledge and retirement decision-making. Rev Econ Stat 90(2): 253-266

Das M, Dominitz J, van Soest A (1999) Comparing predictions and outcomes: theory and application to income changes. J Am Stat Assoc 94: 75-85

De Bresser J, van Soest A (2009) Satisfaction with pension provisions in the netherlands: a panel data analysis. Netspar Discussion Paper DP10/2009-034. Tilburg: Netspar

Delavande A, Rohwedder S (2008) Eliciting subjective probabilities in internet surveys. Public Opin Q 72(5): 886-891

Dominitz J (2001) Estimation of income expectations models using expectations and realizations data. J Econom 102: 165-95

Dominitz J, Manski CF (1997) Using expectations data to study subjective income expectations. J Am Stat Assoc 92 : 855-867

Dominitz J, Manski CF (2005) Measuring and interpreting expectations of equity returns. NBER working paper 11313 , NBER: Cambridge Mass

Dominitz J, Manski CF (2006) Measuring pension-benefit expectations probabilistically. Labour 20: 201-236

De Grip A, Lindeboom M, Montizaan R (2012) Shattered dreams: the effects of changing the pension system late in the game. Econ J 122: 1-25

Feldstein M (1974) Social security, induced retirement, and aggregate capital accumulation. J Polit Econ 82(5): 905-926

Fischhoff B, Bruine de Bruin W (1999) Fifty-fifty = 50 \%? J Behav Decis Mak 12: 149-163

Hudomiet P, Kézdi G, Willis RD (2011) Stock market crash and expectations of american households. J Appl Econom 26(3): $393-415$

Hurd MD (2009) Subjective probabilities in household surveys. Annu Rev Econ 1: 543-564

Hurd MD, McGarry K (1995) Evaluation of the subjective probabilities of survival in the HRS. J of Hum Resour 30: S268-S292

Juster FT, Suzman R (1995) An overview of the health and retirement study. J Hum Resour 30: S7-S56 
Keane M, Runkle D (1990) Testing the rationality of price forecasters: new evidence from panel data. Am Econ Rev 80: 714-34

Lindbeck A, Persson M (2003) The gains from pension reform. J Econ Lit 41 (1): 74-112

Lusardi A, Mitchell O (2007) Baby Boomer retirement security: The roles of planning, financial literacy, and housing wealth. J Monet Econ 54: 205-224

Manski C (2004) Measuring Expectations. Econometrica 72: 1329-1376

Rohwedder S, van Soest A (2006). The Impact of Misperceptions About Social Security on Saving and Well-being. (WP 2006-118), Michigan Retirement Research Center Paper: Ann Arbor

Stephens MJr (2004) Job Loss Expectations, Realizations, and Household Consumption Behavior. Rev Econ Stat 86: 253-269

Van Duin C, Garssen J (2011) Bevolkingsprognose 2010-2060: sterkere vergrijzing, langere levensduur. Bevolkingstrends, 1e kwartaal 2011, The Hague: Statistics Netherlands, pp. 16-23

Van Solinge H, Henkens K (2007) Involuntary retirement: the role of restrictive circumstances, timing, social embeddedness and control. J Gerontol Ser B: Psychol Sci and Soc Sci 62: S295-S305

Van der Wiel KM (2008). Preparing for Policy Changes: Social Security Expectations and Pension Scheme Participation, Netspar Discussion Paper (DP 07/2008-025). Network for Studies on Pensions Aging and Retirement: Tilburg

Van der Wiel KM (2009). Have You Heard the News? How Real-life Expectations React to Publicity, Netspar Discussion Paper (DP 06/2009-031). Network for Studies on Pensions Aging and Retirement: Tilburg

Zaidi A (2010). Fiscal and Pension Sustainability: Present and Future Issues in EU Countries, Policy Brief. European Centre for Social Welfare Policy and Research: Vienna

doi:10.1186/2193-9012-1-2

Cite this article as: Bissonnette and van Soest: The future of retirement and the pension system: How the public's expectations vary over time and across socio-economic groups. IZA Journal of European Labor Studies 2012 1:2.

\section{Submit your manuscript to a SpringerOpen ${ }^{\circ}$ journal and benefit from:}

$\checkmark$ Convenient online submission

$\checkmark$ Rigorous peer review

- Immediate publication on acceptance

- Open access: articles freely available online

- High visibility within the field

Retaining the copyright to your article

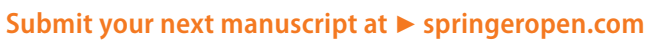

